\title{
Intranasal fusion inhibitory lipopeptide prevents direct-contact SARS-CoV-2 transmission in ferrets
}

\author{
Rory D. de Vries ${ }^{1 *}$, Katharina S. Schmitz ${ }^{1 *}$, Francesca T. Bovier ${ }^{2,3,4 *}$, Camilla Predella ${ }^{2,5}$, Jonathan Khao ${ }^{6}$, \\ Danny Noack', Bart L. Haagmans ${ }^{1}$, Sander Herfst ${ }^{1}$, Kyle N. Stearns ${ }^{2,3,7}$, Jennifer Drew-Bear ${ }^{2,3}$, Sudipta Biswas ${ }^{8}$, \\ Barry Rockx', Gaël McGill ${ }^{6,9}$, N. Valerio Dorrello², Samuel H. Gellman ${ }^{10}$, Christopher A. Alabi ${ }^{8} \dagger$, \\ Rik L. de Swart ${ }^{1} \uparrow$, Anne Moscona ${ }^{2,3,7,11} \uparrow$, Matteo Porotto ${ }^{2,3,4} \uparrow$ \\ ${ }^{1}$ Department of Viroscience, Erasmus MC, Rotterdam, Netherlands. ${ }^{2}$ Department of Pediatrics, Columbia University Irving Medical Center, New York, NY, USA. ${ }^{3}$ Center for \\ Host-Pathogen Interaction, Columbia University Irving Medical Center, New York, NY, USA. "Department of Experimental Medicine, University of Campania "Luigi \\ Vanvitelli," Caserta, Italy. ${ }^{5}$ Department of Biomedical Engineering, Politecnico di Milano, Milan, Italy. ${ }^{6}$ Digizyme Inc., Brookline, MA, USA. ${ }^{7}$ Department of Physiology and \\ Cellular Biophysics, Columbia University Irving Medical Center, New York, NY, USA. ${ }^{8}$ Robert Frederick Smith School of Chemical and Biomolecular Engineering, Cornell \\ University, Ithaca, NY, USA. ${ }^{9}$ Center for Molecular and Cellular Dynamics, Department of Biological Chemistry and Molecular Pharmacology, Harvard Medical School, \\ Boston, MA, USA. ${ }^{10}$ Department of Chemistry, University of Wisconsin-Madison, Madison, WI, USA. ${ }^{11}$ Department of Microbiology and Immunology, Columbia University \\ Irving Medical Center, New York, NY, USA.
}

*These authors contributed equally to this work.

†Corresponding author. Email: caa238@cornell.edu (C.A.A.); r.deswart@erasmusmc.nl (R.L.d.S.);

am939@cumc.columbia.edu (A.M.); mp3509@cumc.columbia.edu (M.P.)

Containment of the COVID-19 pandemic requires reducing viral transmission. SARS-CoV-2 infection is initiated by membrane fusion between the viral and host cell membranes, mediated by the viral spike protein. We have designed lipopeptide fusion inhibitors that block this critical first step of infection, and based on in vitro efficacy and in vivo biodistribution selected a dimeric form for evaluation in an animal model. Daily intranasal administration to ferrets completely prevented SARS-CoV-2 direct-contact transmission during 24-hour co-housing with infected animals, under stringent conditions that resulted in infection of $100 \%$ of untreated animals. These lipopeptides are highly stable and thus may readily translate into safe and effective intranasal prophylaxis to reduce transmission of SARS-CoV-2.

Infection by SARS-CoV-2 requires membrane fusion between the viral envelope and the host cell, at either the cell surface or the endosomal membrane. The fusion process is mediated by the viral transmembrane spike glycoprotein (S). Upon viral attachment or uptake, host factors trigger large-scale conformational rearrangements in S, including a refolding step that leads directly to membrane fusion and viral entry (1-3). Peptides corresponding to the highly conserved heptad repeat (HR, Fig. 1A) domain at the $\mathrm{C}$ terminus of the $\mathrm{S}$ protein (HRC peptides, Fig. 1B) can prevent this refolding and inhibit fusion, thereby preventing infection (4-8). The HRC peptides form six-helix bundle-like assemblies with the extended intermediate form of the S protein trimer, disrupting the structural rearrangement of $S$ that drives membrane fusion (4) (see also movie S1).

Our approach in designing SARS-CoV-2 S-specific fusion inhibitors builds on our previous work that demonstrated that lipid conjugation of HRC-derived inhibitory peptides markedly increases antiviral potency and in vivo half-life $(9$, 10). These peptides successfully inhibit human parainfluenza virus type 3 (HPIV-3), measles virus, influenza virus, and Nipah virus infection $(9,11-13)$. Furthermore, the combination of dimerization and lipopeptide integration into cell membranes protects the respiratory tract and prevents systemic lipopeptide dissemination (14). Lipid-conjugated peptides administered intranasally to animals reached high concentrations both in the upper and lower respiratory tract, and the lipid could be designed to modulate the extent of transit from the lung to the blood and organs $(9,14)$. We propose a SARS-CoV-2 specific lipopeptide as a candidate antiviral for pre-exposure and early post-exposure prophylaxis for SARS-CoV-2 transmission in humans.

We recently described a monomeric SARS-CoV-2 HRClipopeptide fusion inhibitor (4) against SARS-CoV-2 with in vitro and ex vivo efficacy superior to previously described HRC-derived fusion inhibitory peptides $(6,7)$. To further improve antiviral potency, we compared monomeric and dimeric HRC-peptide derivatives (Fig. 1C). Figure 1D shows antiviral potency in a quantitative cell-cell fusion assay of four monomeric and two dimeric SARS-CoV-2 S-derived 36amino acid HRC-peptides (Fig. 1B, see also figs. S1A and S3 for structure and characterization), without or with appended cholesterol. Dimerization increased the peptide potency for both non-lipidated peptides and their lipidated 
counterparts (Fig. 1D). A dimeric cholesterol-conjugated lipopeptide based on the HPIV-3 F protein HRC domain, used as a negative control, did not inhibit fusion at any concentration tested (black line in Fig. 1D, see fig. S1, B and C, for additional negative controls). Among the monomeric lipopeptides, the peptide bearing $\mathrm{PEG}_{24}$ was most potent. The dimeric cholesterol-conjugated peptide ([SARS $\left.\mathrm{HRC}_{-}-\mathrm{PEG}_{4}\right]_{2}$ chol; red line in Fig. 1D) was the most potent lipopeptide against SARS-CoV-2 among our panel. This peptide also robustly inhibited fusion mediated by the $S$ proteins of several emerging SARS-CoV-2 variants [including D614G (15)], the recent variants of concern B.1.1.7 and B.1.351 $(16,17)$ and the S protein of SARS-CoV and MERS-CoV (Fig. 1E). Proposed anchoring of the dimeric lipopeptide in the host cell membrane and interactions with the viral S protein are shown in fig. S2 and movie S1. Collectively, these data suggest that the $\left[\mathrm{SARS}_{\mathrm{HRC}}-\mathrm{PEG}_{4}\right]_{2}$-chol lipopeptide is equipped to combat an evolving pandemic.

For other enveloped respiratory viruses, we previously showed that both ex vivo and in vivo dimeric lipopeptides (administered intranasally) displayed increased retention in the respiratory tract compared to monomeric compounds (14). Here, we compared local and systemic biodistribution of our most potent monomeric and dimeric lipopeptides

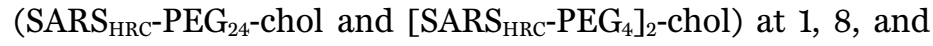
24 hours after intranasal inoculation or subcutaneous injection in humanized K18 hACE2 mice (Fig. 2 and fig. S4). The two lipopeptides reached a similar lung concentration at 1 hour after intranasal administration $(\sim 1$ to $2 \mu \mathrm{M})$. At 8 and 24 hours, the dimeric $\left[\mathrm{SARS}_{\mathrm{HRC}}-\mathrm{PEG}_{4}\right]_{2}$-chol lipopeptide remained at high levels in the lung with minimal entry into the blood, but the monomeric peptide entered the circulation and the lung concentration decreased (Fig. 2A). The dimeric $\left[\mathrm{SARS}_{\mathrm{HRC}}-\mathrm{PEG}_{4}\right]_{2}$-chol lipopeptide was distributed throughout the lung after intranasal administration (Fig. 2B). A cellular toxicity (MTT) assay in primary HAE cells showed minimal toxicity even after 6 days at the highest concentrations tested $(<20 \%$ at $100 \mu \mathrm{M})$, and no toxicity at its $\mathrm{IC}_{90}$ entry inhibitory concentrations ( $35 \mathrm{nM}$ ) (fig. S5). The longer respiratory tract persistence of $\left[\mathrm{SARS}_{\mathrm{HRC}}-\mathrm{PEG}_{4}\right]_{2}$-chol, in concert with its in vitro efficacy, led us to advance this dimeric lipopeptide.

The lead peptide, $\left[\mathrm{SARS}_{\mathrm{HRC}}-\mathrm{PEG}_{4}\right]_{2}$-chol, was assessed for its ability to block entry of SARS-CoV-2 in VeroE6 cells or VeroE6 cells overexpressing the protease TMPRSS2, one of the host factors thought to facilitate viral entry at the cell membrane (2). Whereas viral fusion in VeroE6 cells predominantly occurs after endocytosis, the virus enters TMPRSS2overexpressing cells by fusion at the cell surface, reflecting the entry route in airway cells (18). This difference is highlighted by chloroquine's effectiveness against SARS-CoV-2 infection in Vero cells but failure in TMPRSS2-expressing Vero cells and human lung (19). The $\left[\mathrm{SARS}_{\mathrm{HRC}}-\mathrm{PEG}_{4}\right]_{2}$-chol peptide dissolved in an aqueous buffer containing $2 \%$ dimethylsulfoxide (DMSO) inhibited virus entry after 8 hours with an $\mathrm{IC}_{50}$ $\sim 300 \mathrm{nM}$ in VeroE6 and $\sim 5 \mathrm{nM}$ in VeroE6-TMPRSS2 cells (Fig. 3A). To strengthen translational potential toward human use, the lipopeptide was reformulated in sucrose instead of DMSO, resulting in equivalent in vitro potency (Fig. 3B). A control dimeric fusion-inhibitory lipopeptide directed against HPIV-3 blocked infection by HPIV-3, but did not inhibit SARS-CoV-2 infection. The in vitro efficacy data are summarized in table S1.

Ferrets are an ideal model for assessing respiratory virus transmission, either by direct contact or by aerosol transmission $(20,21)$. Mustelids are highly susceptible to infection with SARS-CoV-2, as also illustrated by frequent COVID-19 outbreaks at mink farms. Direct contact transmission of SARS-CoV in ferrets was demonstrated in 2003 (22), and both direct contact and airborne transmission have been shown in ferrets for SARS-CoV-2 $(20,23)$. Direct contact transmission in the ferret model is highly reproducible (100\% transmission from donor to acceptor animals), but ferrets display limited clinical signs. After infection via direct inoculation or transmission, SARS-CoV-2 can readily be detected in and isolated from the throat and nose, and viral replication leads to seroconversion.

To assess the efficacy of $\left[\mathrm{SARS}_{\mathrm{HRC}}-\mathrm{PEG}_{4}\right]_{2}$-chol in preventing SARS-CoV-2 transmission, naïve ferrets were dosed prophylactically with the lipopeptide before being co-housed with SARS-CoV-2 infected ferrets. In this setup, transmission via multiple routes can theoretically occur (aerosol, orofecal, and scratching or biting), and ferrets are continuously exposed to infectious virus during the period of co-housing, providing a stringent test for antiviral efficacy. The study design is shown in fig. S6. Three donor ferrets (gray in diagram) were inoculated intranasally with $5 \times 10^{5}$ TCID $_{50}$ SARS-CoV-2 on day 0 . Twelve recipient ferrets housed separately were treated by nose drops with a mock preparation (red) or $\left[\mathrm{SARS}_{\mathrm{HRC}}-\mathrm{PEG}_{4}\right]_{2}$-chol peptide (green) 1 and 2 days post-inoc-

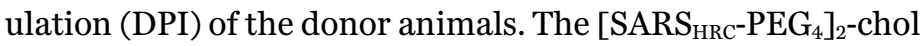
peptides for intranasal administration were dissolved to a concentration of $6 \mathrm{mg} / \mathrm{ml}$ in an aqueous buffer containing $2 \%$ DMSO, administering a final dose of $2.7 \mathrm{mg} / \mathrm{kg}$ to ferrets (450 $\mu \mathrm{l}$, equally divided over both nostrils). Peptide stocks and working dilutions had similar $\mathrm{IC}_{50}$ 's, confirming that peptide-treated ferrets were dosed daily with comparable amounts (fig. S7, A and B). Six hours after the second treatment on 2 DPI, one infected donor ferret (highly positive for SARS-CoV-2 by RT-qPCR) was co-housed with four naïve recipient ferrets (two mock-treated, two peptide-treated). After a 24-hour transmission period in three separate, negatively pressurized HEPA-filtered ABSL3-isolator cages, co-housing was stopped and donor, mock-treated and peptide-treated 
ferrets were housed as separate groups. Additional [SARS $\mathrm{HRC}^{-}$ $\left.\mathrm{PEG}_{4}\right]_{2}$-chol peptide treatments were given to recipient animals on 3 and 4 DPI.

The viral loads (detection of viral genomes via RT-qPCR) for directly inoculated donor animals (gray), mock-treated recipient animals (red) and lipopeptide-treated recipient animals (green) are shown in Fig. 4, A and B. All directly inoculated donor ferrets were productively infected, as shown by SARS-CoV-2 genome detection in throat and nose swabs, and efficiently and reproducibly transmitted the virus to all mock-treated acceptor ferrets (Fig. 4, A and B, red curves). Productive SARS-CoV-2 infection was not detected in the throat or nose of any of the peptide-treated recipient animals (Fig. 4, A and B, green curves). A slight rise in viral loads in samples collected at 3 DPI was detected (at the end of the co-housing), confirming that peptide-treated animals were exposed to SARS-CoV-2. In Fig. 4C the area under the curve (AUC) shows the striking difference between the mock treated and the peptide treated animals. No infectious virus was isolated from lipopeptide-treated ferrets, while infectious virus was detected in all mock-treated ferrets (Fig. 4D). Virus isolation data correlated with genome detection (Fig. 4E).

Seroconversion occurred in donor ferrets and $6 / 6$ mocktreated animals by $21 \mathrm{DPI}$, but in none of the peptide-treated recipient animals, as shown by S- and N-specific IgG enzymelinked immunosorbent assay (ELISA) and virus neutralization (Fig. 4, F to H). Successful challenge infection confirmed that in-host virus replication had been completely blocked by the $\left[\mathrm{SARS}_{\mathrm{HRC}}-\mathrm{PEG}_{4}\right]_{2}$-chol treatment (Fig. 4I and fig. S8) and that none of the peptide-animals were protected, whereas the mock-treated animals (which had seroconverted) were all protected. Collectively, these data show that intranasal prophylactic administration of the $\left[\mathrm{SARS}_{\mathrm{HRC}}-\mathrm{PEG}_{4}\right]_{2}$-chol peptide had protected $6 / 6$ ferrets from transmission and productive infection.

In light of the persistence of the dimeric lipopeptide in the murine lung (Fig. 2 and fig. S4), we assessed the potential for a single administration of sucrose-formulated lipopeptide in a ferret transmission experiment two hours before cohousing to prevent or delay infection. In this experiment, we used a dimeric HPIV-3-specific lipopeptide as mock control (fig. S9). Although sucrose formulation had resulted in promising results in vitro at small scale (Fig. 3B), formulation at larger scale resulted in incomplete dissolution. As a consequence, the sucrose-formulated $\left[\mathrm{SARS}_{\mathrm{HRc}}-\mathrm{PEG}_{4}\right]_{2}$-chol lipopeptide was administered at a substantially lower concentration than in the experiment with the DMSOformulated lipopeptide (fig. S7, C and D). Nevertheless, the SARS-CoV-2 lipopeptide provided a significant level of protection as compared to the HPIV-3 control group, and four out of six SARS-CoV-2 lipopeptide-treated animals were protected against infection. This experiment suggests that single- administration pre-exposure prophylaxis is promising, while the optimal formulation and dosing regimen is an area of ongoing experimentation.

The intranasal $\left[\mathrm{SARS}_{\mathrm{HRC}}-\mathrm{PEG}_{4}\right]_{2}$-chol peptide presented in this study is the first successful prophylaxis that prevents SARS-CoV-2 transmission in a relevant animal model, providing complete protection during a 24-hour period of intense direct contact. Parallel approaches to prevent transmission that target the interaction between S and ACE2 have shown promise in vitro [e.g., the "miniprotein" approach (24)]. The lipopeptide described here acts on the S2 domain after shedding of S1 (fig. S2 and movie S1), and is complementary to strategies that target S1's functions or maintain $\mathrm{S}$ in its prefusion conformation, e.g., synthetic nanobodies $(25,26)$. Fusion-inhibitory lipopeptides could be used for pre- and postexposure prophylaxis in combination with these strategies, and in conjunction with treatments [e.g., ribonucleoside analogs (27)] that reduce replication in a treated infected individual. A combination of drugs that target different aspects of the viral life cycle is likely ideal for this rapidly-evolving virus. Of note, the $\left[\mathrm{SARS}_{\mathrm{HRc}}-\mathrm{PEG}_{4}\right]_{2}$-chol lipopeptide is equally active against several emerging SARS-CoV-2 variants including the D614G as well as the recent variants of concerns (B.1.1.7 and B.1.351). The [SARS $\left.\mathrm{HRC}-\mathrm{PEG}_{4}\right]_{2}$-chol peptide has a long shelf life, does not require refrigeration and can easily be administered, making it particularly suited to treating hard-to-reach populations. This is key in the context of COVID-19, which has reached every community with the burden falling disproportionately on low-income and otherwise marginalized communities. This HRC lipopeptide fusion inhibitor is feasible for advancement to human use and should readily translate into a safe and effective nasal spray or inhalation administered fusion inhibitor for SARS-CoV-2 prophylaxis, supporting containment of the ongoing COVID-19 pandemic.

\section{REFERENCES AND NOTES}

1. F. Li, Structure, function, and evolution of coronavirus spike proteins. Annu. Rev. Virol. 3, 237-261 (2016). doi:10.1146/annurev-virology-110615-042301 Medline

2. M. Hoffmann, H. Kleine-Weber, S. Schroeder, N. Krüger, T. Herrler, S. Erichsen, T. S. Schiergens, G. Herrler, N.-H. Wu, A. Nitsche, M. A. Müller, C. Drosten, S. Pöhlmann, SARS-CoV-2 cell entry depends on ACE2 and TMPRSS2 and is blocked by a clinically proven protease inhibitor. Cell 181, 271-280.e8 (2020). doi:10.1016/i.cell.2020.02.052 Medline

3. Y. Wan, J. Shang, R. Graham, R. S. Baric, F. Li, Receptor recognition by the novel coronavirus from Wuhan: an analysis based on decade-long structural studies of SARS coronavirus. J. Virol. 94, e00127-20 (2020). doi:10.1128/JVL.00127-20 Medline

4. V. K. Outlaw, F. T. Bovier, M. C. Mears, M. N. Cajimat, Y. Zhu, M. J. Lin, A. Addetia, N. A. P. Lieberman, V. Peddu, X. Xie, P.-Y. Shi, A. L. Greninger, S. H. Gellman, D. A. Bente, A. Moscona, M. Porotto, Inhibition of coronavirus entry in vitro and ex vivo by a lipid-conjugated peptide derived from the SARS-CoV-2 spike glycoprotein HRC domain. mBio 11, e01935-20 (2020). doi:10.1128/mBio.01935-20 Medline

5. S. Xia, L. Yan, W. Xu, A. S. Agrawal, A. Algaissi, C. K. Tseng, Q. Wang, L. Du, W. Tan, I. A. Wilson, S. Jiang, B. Yang, L. Lu, A pan-coronavirus fusion inhibitor targeting the HR1 domain of human coronavirus spike. Sci. Adv. 5, eaav4580 (2019). doi:10.1126/sciadv.aav4580 Medline 
6. S. Xia, M. Liu, C. Wang, W. Xu, Q. Lan, S. Feng, F. Qi, L. Bao, L. Du, S. Liu, C. Qin, F. Sun, Z. Shi, Y. Zhu, S. Jiang, L. Lu, Inhibition of SARS-CoV-2 (previously 2019$\mathrm{nCoV}$ ) infection by a highly potent pan-coronavirus fusion inhibitor targeting its spike protein that harbors a high capacity to mediate membrane fusion. Cell Res. 30, 343-355 (2020). doi:10.1038/s41422-020-0305-x Medline

7. Y. Zhu, D. Yu, H. Yan, H. Chong, Y. He, Design of potent membrane fusion inhibitors against SARS-CoV-2, an emerging coronavirus with high fusogenic activity. J. Virol. 94, e00635-20 (2020). doi:10.1128/JVI.00635-20 Medline

8. X. Wang, S. Xia, Q. Wang, W. Xu, W. Li, L. Lu, S. Jiang, Broad-spectrum coronavirus fusion inhibitors to combat COVID-19 and other emerging coronavirus diseases. Int. J. Mol. Sci. 21, 3843 (2020). doi:10.3390/ijms21113843 Medline

9. M. Porotto, B. Rockx, C. C. Yokoyama, A. Talekar, I. Devito, L. M. Palermo, J. Liu, R. Cortese, M. Lu, H. Feldmann, A. Pessi, A. Moscona, Inhibition of Nipah virus infection in vivo: Targeting an early stage of paramyxovirus fusion activation during viral entry. PLOS Pathog. 6, el001168 (2010). doi:10.1371/journal.ppat.1001168 Medline

10. A. Pessi, A. Langella, E. Capitò, S. Ghezzi, E. Vicenzi, G. Poli, T. Ketas, C. Mathieu, R. Cortese, B. Horvat, A. Moscona, M. Porotto, A general strategy to endow natural fusion-protein-derived peptides with potent antiviral activity. PLOS ONE 7 , e36833 (2012). doi:10.1371/journal.pone.0036833 Medline

11. T. N. Figueira, D. A. Mendonça, D. Gaspar, M. N. Melo, A. Moscona, M. Porotto, M. A. R. B. Castanho, A. S. Veiga, Structure-stability-function mechanistic links in the anti-measles virus action of tocopherol-derivatized peptide nanoparticles. ACS Nano 12, 9855-9865 (2018). doi:10.1021/acsnano.8b01422 Medline

12. T. N. Figueira, M. T. Augusto, K. Rybkina, D. Stelitano, M. G. Noval, O. E. Harder, A. S. Veiga, D. Huey, C. A. Alabi, S. Biswas, S. Niewiesk, A. Moscona, N. C. Santos, M. A. R. B. Castanho, M. Porotto, Effective in vivo targeting of influenza virus through a cell-penetrating/fusion inhibitor tandem peptide anchored to the plasma membrane. Bioconjug. Chem. 29, 3362-3376 (2018). doi:10.1021/acs. bioconjchem.8b00527 Medline

13. C. Mathieu, M. T. Augusto, S. Niewiesk, B. Horvat, L. M. Palermo, G. Sanna, S. Madeddu, D. Huey, M. A. R. B. Castanho, M. Porotto, N. C. Santos, A. Moscona, Broad spectrum antiviral activity for paramyxoviruses is modulated by biophysical properties of fusion inhibitory peptides. Sci. Rep. 7, 43610 (2017). doi:10.1038/srep43610 Medline

14. T. N. Figueira, L. M. Palermo, A. S. Veiga, D. Huey, C. A. Alabi, N. C. Santos, J. C. Welsch, C. Mathieu, B. Horvat, S. Niewiesk, A. Moscona, M. A. R. B. Castanho, M. Porotto, In vivo efficacy of measles virus fusion protein-derived peptides is modulated by the properties of self-assembly and membrane residence. J. Virol. 91, e01554-16 (2016). doi:10.1128/JVI.01554-16 Medline

15. L. Zhang, C. B. Jackson, H. Mou, A. Ojha, H. Peng, B. D. Quinlan, E. S. Rangarajan, A. Pan, A. Vanderheiden, M. S. Suthar, W. Li, T. Izard, C. Rader, M. Farzan, H. Choe, SARS-CoV-2 spike-protein D614G mutation increases virion spike density and infectivity. Nat. Commun. 11, 6013 (2020). doi:10.1038/s41467-020-19808-4 Medline

16. A. Muik, A.-K. Wallisch, B. Sänger, K. A. Swanson, J. Mühl, W. Chen, H. Cai, D. Maurus, R. Sarkar, Ö. Türeci, P. R. Dormitzer, U. Şahin, Neutralization of SARSCoV-2 lineage B.1.1.7 pseudovirus by BNT162b2 vaccine-elicited human sera. Science eabg6105 (2021). doi:10.1126/science.abg6105 Medline

17. K. Wu, A. P. Werner, J. I. Moliva, M. Koch, A. Choi, G. B. E. Stewart-Jones, H. Bennett, S. Boyoglu-Barnum, W. Shi, B. S. Graham, A. Carfi, K. S. Corbett, R. A. Seder, D. K. Edwards, mRNA-1273 vaccine induces neutralizing antibodies against spike mutants from global SARS-CoV-2 variants. bioRxiv 2021.01.25.427948 [Preprint]. 25 January 2021. https://doi.org/10.1101/2021.01.25.427948.

18. A. Z. Mykytyn, T. I. Breugem, S. Riesebosch, D. Schipper, P. B. van den Doel, R. J. Rottier, M. M. Lamers, B. L. Haagmans, SARS-CoV-2 entry into human airway organoids is serine protease-mediated and facilitated by the multibasic cleavage site. eLife 10, e64508 (2021). doi:10.7554/eLife.64508 Medline

19. M. Hoffmann, K. Mösbauer, H. Hofmann-Winkler, A. Kaul, H. Kleine-Weber, N. Krüger, N. C. Gassen, M. A. Müller, C. Drosten, S. Pöhlmann, Chloroquine does not inhibit infection of human lung cells with SARS-CoV-2. Nature 585, 588-590 (2020). doi:10.1038/s41586-020-2575-3 Medline

20. M. Richard, A. Kok, D. de Meulder, T. M. Bestebroer, M. M. Lamers, N. M. A. Okba, M. Fentener van Vlissingen, B. Rockx, B. L. Haagmans, M. P. G. Koopmans, R. A. M. Fouchier, S. Herfst, SARS-CoV-2 is transmitted via contact and via the air between ferrets. Nat. Commun. 11, 3496 (2020). doi:10.1038/s41467-02017367-2 Medline

21. V. J. Munster, E. de Wit, J. M. A. van den Brand, S. Herfst, E. J. A. Schrauwen, T. M. Bestebroer, D. van de Vijver, C. A. Boucher, M. Koopmans, G. F. Rimmelzwaan, T. Kuiken, A. D. M. E. Osterhaus, R. A. M. Fouchier, Pathogenesis and transmission of swine-origin $2009 \mathrm{~A}(\mathrm{H} 1 \mathrm{N1})$ influenza virus in ferrets. Science 325, 481-483 (2009). doi:10.1126/science.1177127 Medline

22. B. E. Martina, B. L. Haagmans, T. Kuiken, R. A. M. Fouchier, G. F. Rimmelzwaan, G. Van Amerongen, J. S. M. Peiris, W. Lim, A. D. M. E. Osterhaus, SARS virus infection of cats and ferrets. Nature 425, 915 (2003). doi:10.1038/425915a Medline

23. Y. I. Kim, S.-G. Kim, S.-M. Kim, E.-H. Kim, S.-J. Park, K.-M. Yu, J.-H. Chang, E. J. Kim, S. Lee, M. A. B. Casel, J. Um, M.-S. Song, H. W. Jeong, V. D. Lai, Y. Kim, B. S. Chin, J.-S. Park, K.-H. Chung, S.-S. Foo, H. Poo, I.-P. Mo, O.-J. Lee, R. J. Webby, J. U. Jung, Y. K. Choi, Infection and rapid transmission of SARS-CoV-2 in ferrets. Cell Host Microbe 27, 704-709.e2 (2020). doi:10.1016/j.chom.2020.03.023 Medline

24. L. Cao, I. Goreshnik, B. Coventry, J. B. Case, L. Miller, L. Kozodoy, R. E. Chen, L. Carter, A. C. Walls, Y.-J. Park, E.-M. Strauch, L. Stewart, M. S. Diamond, D. Veesler, D. Baker, De novo design of picomolar SARS-CoV-2 miniprotein inhibitors. Science 370, 426-431 (2020). doi:10.1126/science.abd9909 Medline

25. M. Schoof, B. Faust, R. A. Saunders, S. Sangwan, V. Rezelj, N. Hoppe, M. Boone, C. B. Billesbølle, C. Puchades, C. M. Azumaya, H. T. Kratochvil, M. Zimanyi, I. Deshpande, J. Liang, S. Dickinson, H. C. Nguyen, C. M. Chio, G. E. Merz, M. C. Thompson, D. Diwanji, K. Schaefer, A. A. Anand, N. Dobzinski, B. S. Zha, C. R. Simoneau, K. Leon, K. M. White, U. S. Chio, M. Gupta, M. Jin, F. Li, Y. Liu, K. Zhang, D. Bulkley, M. Sun, A. M. Smith, A. N. Rizo, F. Moss, A. F. Brilot, S. Pourmal, R. Trenker, T. Pospiech, S. Gupta, B. Barsi-Rhyne, V. Belyy, A. W. Barile-Hill, S. Nock, Y. Liu, N. J. Krogan, C. Y. Ralston, D. L. Swaney, A. García-Sastre, M. Ott, M. Vignuzzi, QCRG Structural Biology Consortium, P. Walter, A. Manglik, An ultrapotent synthetic nanobody neutralizes SARS-CoV-2 by locking Spike into an inactive conformation. bioRxiv 2020.08.08.23846 [Preprint]. 17 August 2020. https://doi.org/10.1101/2020.08.08.238469.

26. M. Schoof, B. Faust, R. A. Saunders, S. Sangwan, V. Rezelj, N. Hoppe, M. Boone, C. B. Billesbølle, C. Puchades, C. M. Azumaya, H. T. Kratochvil, M. Zimanyi, I. Deshpande, J. Liang, S. Dickinson, H. C. Nguyen, C. M. Chio, G. E. Merz, M. C. Thompson, D. Diwanii, K. Schaefer, A. A. Anand, N. Dobzinski, B. S. Zha, C. R. Simoneau, K. Leon, K. M. White, U. S. Chio, M. Gupta, M. Jin, F. Li, Y. Liu, K. Zhang D. Bulkley, M. Sun, A. M. Smith, A. N. Rizo, F. Moss, A. F. Brilot, S. Pourmal, R. Trenker, T. Pospiech, S. Gupta, B. Barsi-Rhyne, V. Belyy, A. W. Barile-Hill, S. Nock, Y. Liu, N. J. Krogan, C. Y. Ralston, D. L. Swaney, A. García-Sastre, M. Ott, M. Vignuzzi, P. Walter, A. Manglik; QCRG Structural Biology Consortium, An ultrapotent synthetic nanobody neutralizes SARS-CoV-2 by stabilizing inactive Spike. Science 370, 1473-1479 (2020). doi:10.1126/science.abe3255 Medline

27. R. M. Cox, J. D. Wolf, R. K. Plemper, Therapeutically administered ribonucleoside analogue MK-4482/EIDD-2801 blocks SARS-CoV-2 transmission in ferrets. Nat. Microbiol. 6, 11-18 (2021). doi:10.1038/s41564-020-00835-2 Medline

28. T. A. Halgren, B. L. Bush, The Merck molecular force field (MMFF94). Extension and application. Abstr. Pap. Am. Chem. Soc. 212, 2-Comp (1996).

29. R. B. Best, X. Zhu, J. Shim, P. E. M. Lopes, J. Mittal, M. Feig, A. D. Mackerell Jr., Optimization of the additive CHARMM all-atom protein force field targeting improved sampling of the backbone $\varphi, \psi$ and side-chain $\chi_{1}$ and $\chi_{2}$ dihedral angles. J. Chem. Theory Comput. 8. 3257-3273 (2012). doi:10.1021/ct300400x Medline

30. S. J. Marrink, H. J. Risselada, S. Yefimov, D. P. Tieleman, A. H. de Vries, The MARTINI force field: Coarse grained model for biomolecular simulations. J. Phys. Chem. B 111, 7812-7824 (2007). doi:10.1021/jp071097f Medline

31. Y. Cai, J. Zhang, T. Xiao, H. Peng, S. M. Sterling, R. M. Walsh Jr., S. Rawson, S. RitsVolloch, B. Chen, Distinct conformational states of SARS-CoV-2 spike protein. Science 369, 1586-1592 (2020). doi:10.1126/science.abd4251 Medline

32. S. Hakansson-McReynolds, S. Jiang, L. Rong, M. Caffrey, Solution structure of the severe acute respiratory syndrome-coronavirus heptad repeat 2 domain in the prefusion state. J. Biol. Chem. 281, 11965-11971 (2006). doi:10.1074/ibc.M601174200 Medline

33. G. J. van Doornum, M. Schutten, J. Voermans, G. J. Guldemeester, H. G. Niesters, Development and implementation of real-time nucleic acid amplification for the detection of enterovirus infections in comparison to rapid culture of various clinical specimens. J. Med. Virol. 79, 1868-1876 (2007). doi:10.1002/jmv.21031 
Medline

34. V. M. Corman, O. Landt, M. Kaiser, R. Molenkamp, A. Meijer, D. K. W. Chu, T. Bleicker, S. Brünink, J. Schneider, M. L. Schmidt, D. G. J. C. Mulders, B. L. Haagmans, B. van der Veer, S. van den Brink, L. Wijsman, G. Goderski, J.-L. Romette, J. Ellis, M. Zambon, M. Peiris, H. Goossens, C. Reusken, M. P. G. Koopmans, C. Drosten, Detection of 2019 novel coronavirus (2019-nCoV) by realtime RT-PCR. Euro Surveill. 25, 2000045 (2020). doi:10.2807/15607917.ES.2020.25.3.2000045 Medline

\section{ACKNOWLEDGMENTS}

We thank J. S. Orange, S. G. Kernie, M. Lamers, E. Verveer, A. Mykytyn and M. Koopmans for their contributions to this study. Funding: This work was supported by funding from the National Institutes of Health (Al146980, Al121349, and NS091263 to M.P., Al114736 to A.M., HHSN272201400008C to S.H.), the Sharon Golub Fund at Columbia University Irving Medical Center (CUIMC), the Children's Health Innovation Nucleation Fund of the Pediatrics Department at CUIMC and a Harrington Discovery Institute COVID-19 Award to A.M. A.M. is the inaugural Sherie L. Morrison Professor of Immunology. Author contributions: Conceptualization: R.D.d.V., S.H.G., C.A.A., R.L.d.S., A.M., M.P. Formal analysis: R.D.d.V., K.S.S., F.T.B., C.P., N.V.D., C.A.A., R.L.d.S., A.M., M.P. Funding acquisition: B.L.H., R.L.d.S., A.M., M.P. Investigation: R.D.d.V., K.S.S., F.T.B., C.P., J.K., D.N., K.N.S., S.H., J.D.-B., S.B., G.M., N.V.D., S.H.G., C.A.A., R.L.d.S., A.M., M.P. Resources: B.L.H., B.R., N.V.D., C.A.A., R.L.d.S., A.M., M.P. Supervision: R.L.d.S., N.V.D., C.A.A., A.M., M.P. Visualization: R.D.d.V., K.S., F.T.B., J.K., G.M., N.V.D., S.H.G., C.A.A., A.M., M.P. Writing - original draft: R.D.d.V., R.L.d.S., A.M., M.P. Writing - final version: all co-authors provided feedback to the final draft. Competing interests: R.D.d.V., F.T.B., R.L.d.S., A.M. and M.P. are listed as inventors of [SARS HRC-PEG ] $_{2}$-chol on a provisional patent application covering findings reported in this manuscript. Data and materials availability: All data are available in the manuscript or the supplementary materials. Materials are available by MTA with the Trustees of Columbia University, NYC. This work is licensed under a Creative Commons Attribution 4.0 International (CC BY 4.0) license, which permits unrestricted use, distribution, and reproduction in any medium, provided the original work is properly cited. To view a copy of this license, visit https://creativecommons.org/licenses/by/4.0/. This license does not apply to figures/photos/artwork or other content included in the article that is credited to a third party; obtain authorization from the rights holder before using such material. Reagents are available from the corresponding authors under a material agreement with Columbia University.

\section{SUPPLEMENTARY MATERIALS}

science.sciencemag.org/cgi/content/full/science.abf4896/DC1

Materials and Methods

Figs. S1 to S10

Table S1

References (28-34)

MDAR Reproducibility Checklist

Movie S1

29 October 2020; resubmitted 4 January 2021

Accepted 9 February 2021

Published online 17 February 2021

10.1126/science.abf4896 

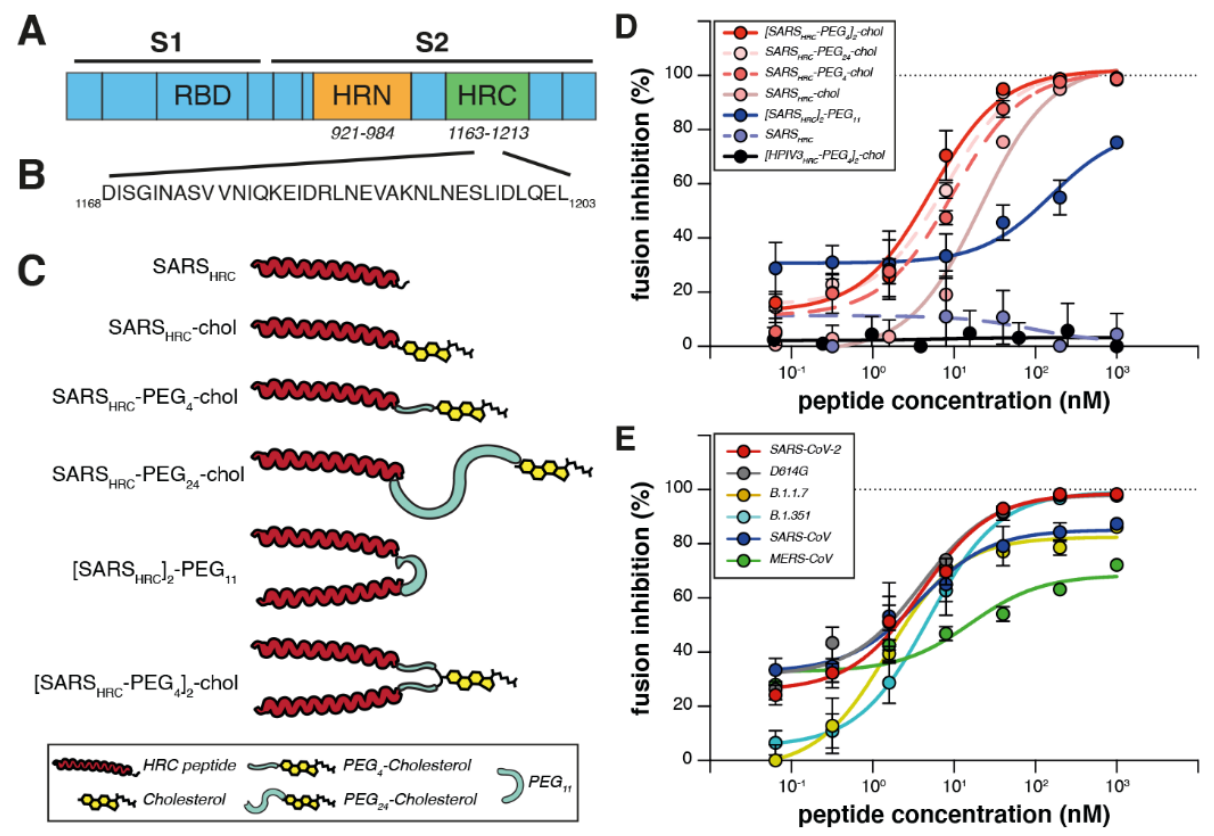

Fig. 1. Peptide-lipid conjugates that inhibit SARS-CoV-2 spike (S)-mediated fusion. (A) The functional domains of SARS-CoV-2 S protein: receptor-binding domain (RBD) and heptad repeats (HRN and HRC) are indicated. (B) Sequence of the peptides derived from the HRC domain of SARS-CoV-2 S. (C) Monomeric and dimeric forms of lipid tagged SARS-CoV-2 inhibitory peptides that were assessed in cell-cell fusion assays. (D) Cell-cell fusion assays with different inhibitory peptides. The percentage inhibition is shown for six different SARS-CoV-2-specific peptides and a control HPIV-3-specific peptide at increasing concentrations. Percent inhibition was calculated as the ratio of the relative luminescence units in the presence of a specific concentration of inhibitor and the relative luminescence units in the absence of inhibitor, corrected for background luminescence. $\%$ inhibition $=100 \times[1-$ (luminescence at $X-$ background)/(luminescence in absence of inhibitor - background)]. The difference between the results for [SARS $\left.{ }_{H R C}-P E G_{4}\right]_{2}$-chol and $S A R S_{H R C}-P E G_{4}$-chol lipopeptides was statistically significant (two-way ANOVA, $P<0.0001$ ). (E) Fusion inhibitory activity of $\left[\mathrm{SARS}_{\mathrm{HRC}}-\mathrm{PEG}_{4}\right]_{2}$-chol peptide against emerging SARS-CoV-2 S variants, MERS-CoV-2 $S$, and SARS-CoV S. Data in (D) and (E) are means \pm standard error of the mean (SEM) from three separate experiments with the curve representing a four-parameter doseresponse model. 


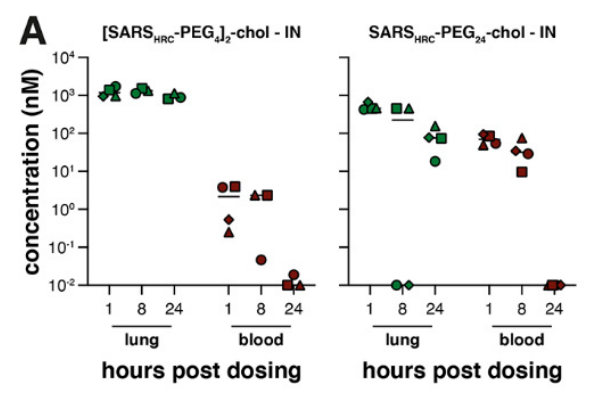

B

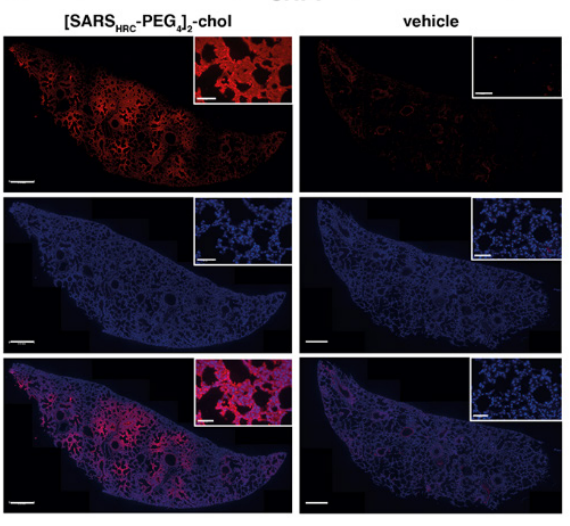

Fig. 2. Biodistribution of $\left[\mathrm{SARS}_{\mathrm{HRC}}-\mathrm{PEG}_{4}\right]_{2}-\mathrm{chol}$ and $S A R S_{H R C}-P E_{24}$ peptides after intranasal administration to mice. (A) The concentration of lipopeptides ( $y$ axis) was measured by ELISA in lung homogenates and plasma samples (peptide-treated $n=3$ to 4 , mock $n=1$ ). Median is indicated by horizontal bar. (B) Lung sections of [SARS HRC $^{-}$ $\left.\mathrm{PEG}_{4}\right]_{2}$-chol-treated (or vehicle-treated) mice were stained with anti-SARS-HRC antibody (red) confirming broad distribution of $\left[\mathrm{SARS}_{\mathrm{HRC}}-\mathrm{PEG}_{4}\right]_{2}$-chol in the lung (8 hours post-inoculation, $8 \mathrm{HPI}$ ). Scale bar $=500 \mu \mathrm{m}$ in lung tile scan, $50 \mu \mathrm{m}$ in magnification, representative images and a full tile scan are shown. Nuclei were counterstained with DAPI (blue).
A

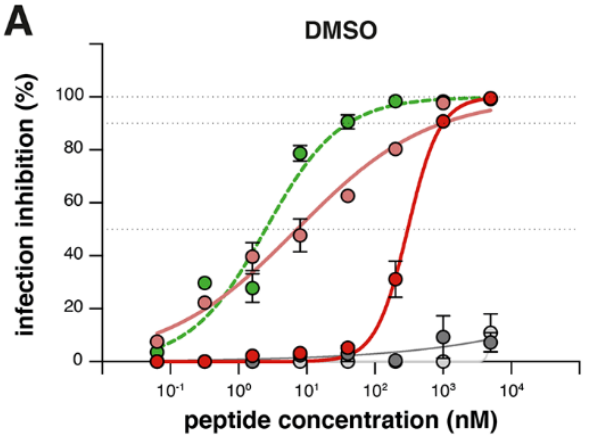

- - ISARS ${ }_{\text {HPC }}-P E G_{\text {d }}$-chol on VerOE

$\left[H P I V 3_{H A C}-P E G_{4}\right]_{2}-$ chol on VeroE 6
B

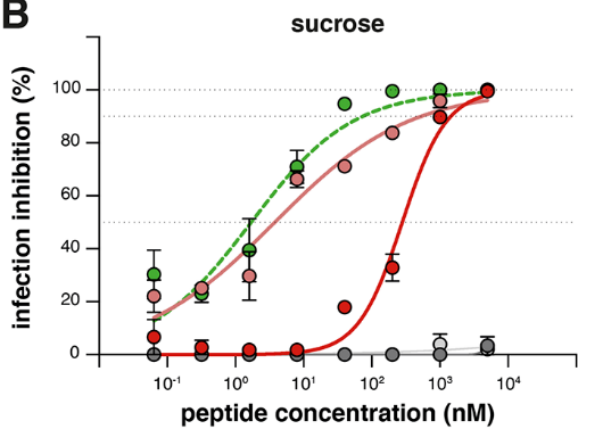

- - [SARS HAC $\left._{-}-P E G_{4}\right]_{2}$-chol on VeroE6-TMPRSS2

- $\left[H P I V 3_{H A C}-P E G_{4}\right]_{2}-c h o l$ against HPIV3

Fig. 3. Inhibition of infectious SARS-CoV-2 entry by [SARS $\left.\mathrm{HRC}_{-}-\mathrm{PEG}_{4}\right]_{2}-$ chol and [HPIV-3 $\left.{ }_{\mathrm{HRC}}-\mathrm{PEG}_{4}\right]_{2}$-chol peptides. (A and $\mathrm{B}$ ) The percentage inhibition of infection is shown on VeroE6 and VeroE6-TMPRSS2 cells

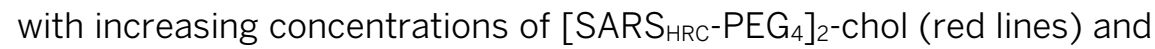
[HPIV-3 HRC $\left.-\mathrm{PEG}_{4}\right]_{2}$-chol (gray lines). DMSO-formulated (A) and sucroseformulated stocks (B) were tested side-by-side. Mean \pm SEM of triplicates are shown, dotted lines show 50\% and 90\% inhibition. Additionally, the potency of [HPIV-3 $\left.\left.3_{\mathrm{HRC}}-\mathrm{PEG}\right]_{2}\right]_{2}-\mathrm{chol}$ was confirmed by inhibition of infectious HPIV-3 entry (dotted green lines, performed on Vero cells). 

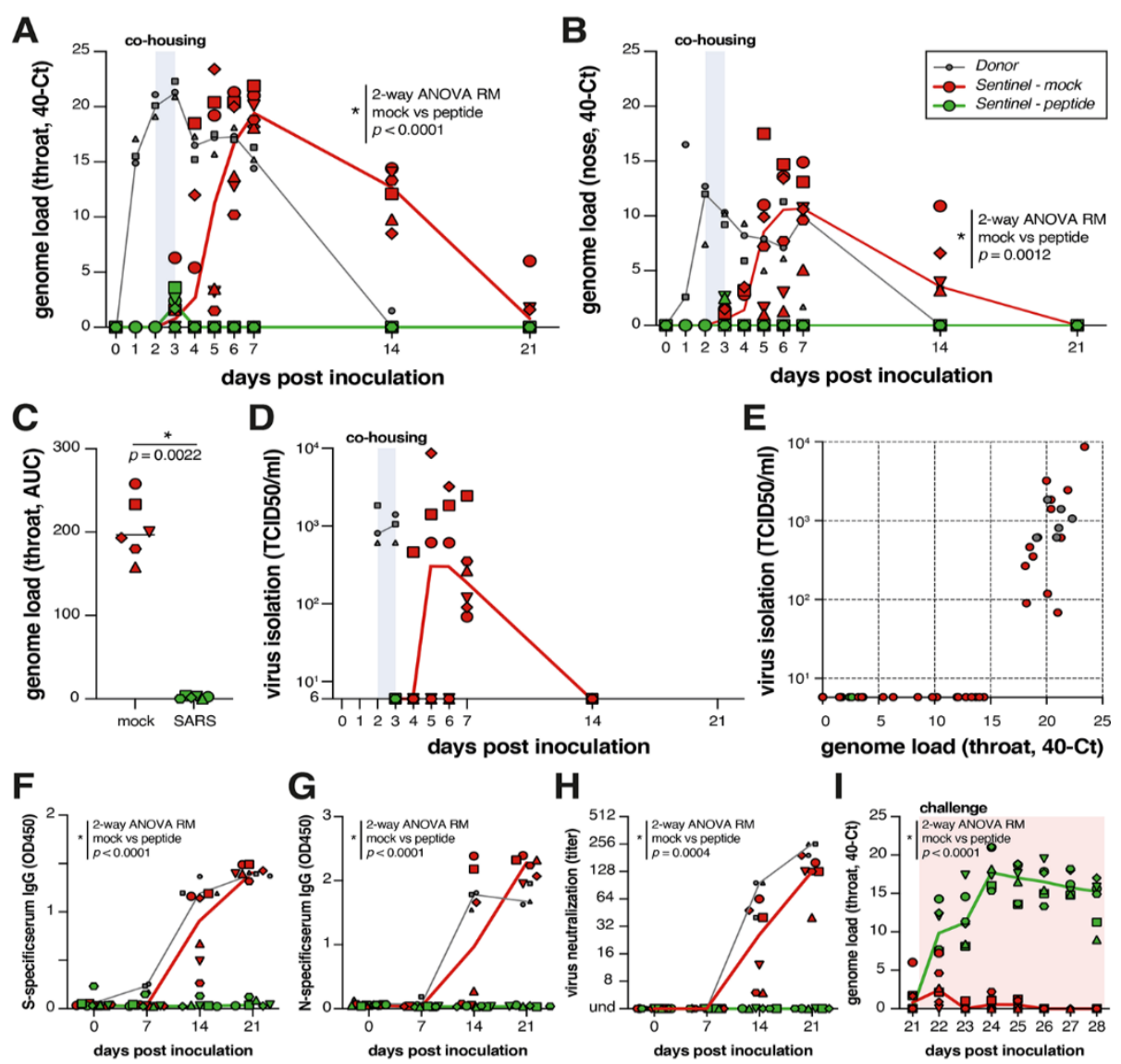

Fig. 4. $\left[\mathrm{SARS}_{\mathrm{HRC}}-\mathrm{PEG}_{4}\right]_{2}$-chol prevents SARS-CoV-2 transmission in vivo. (A and $B$ ) Viral loads detected in throat (A) and nose (B) swabs by RT-qPCR. (C) Comparison of the area under the curve (AUC) from genome loads reported in B for mock- and peptide-treated sentinels. (D) Viral loads detected in throat swabs by virus isolation on VeroE6. (E) Correlation between viral loads in the throat as detected via RT-qPCR and virus isolation. Presence of anti-S (F) or anti-N (G) antibodies was determined by IgG ELISA assay. Presence of neutralizing antibodies was determined in a virus neutralization assay $(H)$. Virus neutralizing antibodies are displayed as the endpoint serum dilution factor that blocks SARS-CoV-2 replication. Direct inoculation of peptide-treated or mock-treated animals with SARS-CoV-2 led to productive infection in only the previously peptide-treated animals (I), in the absence of Sspecific, $\mathrm{N}$-specific and neutralizing antibodies. Donor animals shown in gray, mock-treated animals in red, peptide-treated animals in green. Symbols correspond to individual animals (defined in fig. S6). Line graphs in (A), (B), (D), and (F) to (I) connect the median of individual animals per time point. Mock- and peptide-treated groups were compared via two-way ANOVA repeated measures [(A), $(B)$, and $(F)$ to (I)] or Mann-Whitney test (C). 